\title{
Two Mutations within a Feline Mucopolysaccharidosis Type VI Colony Cause Three Different Clinical Phenotypes
}

\author{
Allison C. Crawley, Gouri Yogalingam, Vivienne J. Muller, and John J. Hopwood \\ Lysosomal Diseases Research Unit, Department of Chemical Pathology, Women's and Children's Hospital, North Adelaide, \\ South Australia, 5006, Australia
}

\begin{abstract}
Mucopolysaccharidosis type VI (MPS VI) is a lysosomal storage disease caused by a deficiency of $N$-acetylgalactosamine-4-sulfatase (4S). A feline MPS VI model used to demonstrate efficacy of enzyme replacement therapy is due to the homozygous presence of an L476P mutation in 4-sulfatase. An additional mutation, D520N, inherited independently from L476P and recently identified in the same family of cats, has resulted in three clinical phenotypes. L476P homozygotes exhibit dwarfism and facial dysmorphia due to epiphyseal dysplasia, abnormally low leukocyte $4 \mathrm{~S} / \beta$ hexosaminidase ratios, dermatan sulfaturia, lysosomal inclusions in most tissues including chondrocytes, corneal clouding, degenerative joint disease, and abnormal leukocyte inclusions. Similarly, D520N/D520N and L476P/D520N cats have abnormally low leukocyte $4 \mathrm{~S} / \beta$ hexosaminidase ratios, mild dermatan sulfaturia, lysosomal inclusions in some chondrocytes, and abnormal leukocyte inclusions. However, both have normal growth and appearance. In addition, L476P/D520N cats have a high incidence of degenerative joint disease. We conclude that L476P/D520N cats have a very mild MPS VI phenotype not previously described in MPS VI humans. The study of L476P/D520N and D520N/ D520N genotypes will improve understanding of genotype to phenotype correlations and the pathogenesis of skeletal dysplasia and joint disease in MPS VI, and will assist in development of therapies to prevent lysosomal storage in chondrocytes. (J. Clin. Invest. 1998. 101:109-119.) Key words: mucopolysaccharidosis VI • lysosomal storage diseases - genetics, medical $\cdot$ joint diseases - disease models, animal
\end{abstract}

\section{Introduction}

Mucopolysaccharidosis type VI (MPS VI; ${ }^{1}$ Maroteaux-Lamy syndrome) is caused by a deficiency of the lysosomal enzyme $N$-acetylgalactosamine-4-sulfatase (4S, E.C.3.1.6.1), which is

Address correspondence to John J. Hopwood, Lysosomal Diseases Research Unit, Department of Chemical Pathology, Women's and Children's Hospital, 72 King William Road, North Adelaide, South Australia, 5006, Australia. Phone: 61-8-8204-7293; FAX: 61-8-82047100; E-mail: jhopwood@medicine.adelaide.edu.au

Received for publication 16 June 1997 and accepted in revised form 3 November 1997.

J. Clin. Invest.

(C) The American Society for Clinical Investigation, Inc. 0021-9738/98/01/0109/11 \$2.00

Volume 101, Number 1, January 1998, 109-119

http://www.jci.org essential for the degradation of the glycosaminoglycan (GAG) dermatan sulfate (DS). This results in widespread lysosomal storage of this substrate in connective tissues. Clinical presentation is variable, and severely affected patients exhibit dwarfism due to epiphyseal dysplasia, characteristic coarse facies, heart valve thickening, carpal tunnel syndrome, joint stiffness, corneal clouding, narrowing of airways, abnormal leukocyte granulation, and dermatan sulfaturia, with death usually in the second decade $(1,2)$. Less severely affected patients can have almost normal skeletal growth but may have cardiac insufficiency due to valve thickening, less severe joint stiffness and skeletal abnormalities, carpal tunnel syndrome, spinal cord compression due to dural thickening, and less severe corneal clouding (3-6).

The same degree of phenotypic variation in MPS animal models has not been described previously. This may be due to the difficulty in observing subtle clinical changes that would lead to further evaluation for specific disorders. MPS VI was originally described in the United States in three Siamese cats, none of which had common ancestors, although an extensive pedigree was not available (7). These cats were all similarly affected, with severe skeletal abnormalities. MPS VI has since been diagnosed in Siamese (8), long-haired Siamese (9), and domestic long-haired (10) cat breeds from different locations including Italy, and all appear similarly affected. Disease characteristics in feline MPS VI closely parallel disease in humans clinically and histologically, with lysosomal storage in many cell types including chondrocytes, fibroblasts, Kupffer cells (liver), smooth muscle cells, and corneal keratocytes (11). Molecular analysis of our cat colony derived from "family 3" cats (7) has shown MPS VI-affected cats are homoallelic for an amino acid substitution at codon 476, altering a leucine to a proline codon (L476P) (12). Expression of the L476P allele resulted in low yields of an inactive $4 \mathrm{~S}$ precursor protein (12). L476P homozygotes have been used to evaluate the efficacy of enzyme replacement therapy $(13,14)$.

MPS VI patients generally have up to $5 \%$ residual 4 S activity in leukocytes and fibroblasts, and therefore we presume that this level is similar in other cell types. Recent studies have demonstrated some correlation between this $4 \mathrm{~S}$ activity, genotype, and disease phenotype (15-17). A better understanding of genotype to phenotype correlations has been important in patient diagnosis, prognosis, management, and evaluation of therapies. In particular, knowledge of the genotype to phenotype relationship has been invaluable in assessing efficacy of

1. Abbreviations used in this paper: $4 \mathrm{~S}, N$-acetylgalactosamine-4-sulfatase; $4 \mathrm{~S} / \beta$ hex, $4 \mathrm{~S} / \beta$ hexosaminidase ratio; DS, dermatan sulfate; HRE, high-resolution electrophoresis; GAG, glycosaminoglycan; MPS VI, mucopolysaccharidosis type VI; N/N, D520N homozygote; $\mathrm{P} / \mathrm{N}$, L476P and D520N compound heterozygote; P/P, L476P homozygote; +/+, normal genotype; +/N, D520N heterozygote; +/P, L476P heterozygote. 
bone marrow transplants (18). A threshold of $\sim 5 \%$ residual $4 \mathrm{~S}$ activity has been suggested as the level of $4 \mathrm{~S}$ needed to prevent or remove lysosomal storage (15). In enzyme replacement therapy studies in L476P homozygous MPS VI cats, weekly intravenous administration of recombinant human $4 \mathrm{~S}$ from birth lead to complete reversal of lysosomal storage in liver, heart valve, skin, kidney interstitium, brain perivascular cells, and dura, but not in cartilage, cornea, and white blood cells (14). Therapy also improved bone growth and bone histomorphometric parameters (19). Effective enzyme replacement therapy relies on the process of receptor-mediated uptake and translocation via the endocytic pathway of recombinant enzyme to the lysosomes, via cell surface receptors such as the mannose6-phosphate receptor. Cell types resistant to therapy suggest either inadequate amounts of $4 \mathrm{~S}$ reaching lysosomes due to different receptors or inability to diffuse through surrounding tissues, or increased DS metabolism and hence $4 \mathrm{~S}$ requirements.

The availability of MPS animal models with both mild and severe phenotypes would enable studies to better understand the pathophysiology of disease processes by correlating the level and quality of enzyme activity to histopathological changes in different cell types, and the clinical outcome of these changes. Differences in the degree of lysosomal storage in various tissues between the different phenotypes would indicate which tissues had sufficient enzyme levels to prevent or reduce lysosomal storage in the milder phenotype, and which tissues had high substrate turnover and hence persistent lysosomal storage in both phenotypes. These differences may then lead to different clinical outcomes which may indicate involvement of particular cell types in the development of disease. In addition, due to lower rates of substrate accumulation in the milder phenotype, it would be easier to determine the amount of enzyme required for reversal of storage in certain cell types. This may be useful in improving therapies directed toward tissues with poor enzyme penetration or uptake, or high substrate turnover, especially as new therapies are developed such as enzyme and gene replacement therapy.

A second feline MPS VI mutation was discovered recently within our MPS VI cat colony which involved a base change leading to an amino acid substitution at codon 520 (D520N) (Yogalingam, G., J.J. Hopwood, A. Crawley, and D. Anson, manuscript in preparation). This has led to a unique situation where homoallelic (for both L476P and D520N mutations) and heteroallelic animals of fairly uniform genetic background could be studied. We describe the clinical, biochemical, and histological features of compound heterozygote cats (L476P/ D520N), and cats homozygous for the D520N allele, compared with cats homozygous for the L476P allele which exhibit a severe MPS VI phenotype.

\section{Methods}

Experimental animals. All cats used in these studies were bred in an outdoor housed colony originally established from five family 3 heterozygotes obtained in 1985 from M. Haskins (School of Veterinary Medicine, University of Pennsylvania, Philadelphia, PA) (7). The disease originally occurred in purebred Siamese cats. Unrelated normal cats were intermittently introduced to the colony for subsequent outbreeding. Genotype of animals within the colony was established from PCR-based analysis of dried blood spots or DNA prepared from white cell pellets. Restriction analysis of PCR products using
HaeIII restriction enzyme was used to identify an L to $\mathrm{P}$ change at codon 476 (12), and BslI or AvaII to identify a D to N change at codon 520 (Yogalingam, G., J.J. Hopwood, A. Crawley, and D. Anson, manuscript in preparation). There were six genotypes observed within the colony due to both mutations: normal for both alleles (annotated +/+), L476P homozygotes (P/P), L476P heterozygote (+/P), D520N homozygotes $(\mathrm{N} / \mathrm{N})$, D520N heterozygote $(+/ \mathrm{N})$, and L476P and D520N compound heterozygotes $(\mathrm{P} / \mathrm{N})$. The $\mathrm{P} / \mathrm{Ps}$ exhibit severe MPS VI and have been described previously $(13,14,19)$.

Due to the D520N mutation being identified $1 \mathrm{yr}$ after the L476P mutation, most N/Ns and $+/ \mathrm{Ns}$ were culled from the colony to optimize breeding of $\mathrm{P} / \mathrm{Ps}$ for other studies. Therefore, this study is largely a retrospective study of archived material, with only small numbers of young live animals from some genotypes available for this study.

Enzymology. Peripheral leukocytes were prepared using dextran sedimentation (20). Leukocyte $4 \mathrm{~S}$ activities, expressed as $4 \mathrm{~S} / \beta$ hexosaminidase ( $4 \mathrm{~S} / \mathrm{\beta hex})$ ratios, were measured using radiolabeled trisaccharide substrate (21). One-way ANOVA and the Tukey-HSD test for posttesting was used for statistical comparison of $4 \mathrm{~S} / \beta$ hex ratios between $\mathrm{N} / \mathrm{N}, \mathrm{P} / \mathrm{N}$, and $\mathrm{P} / \mathrm{P}$ genotypes, accepting $P<0.05$ as statistically significant.

Qualitative urinalysis. Urine high-resolution electrophoresis (HRE) allows visualization of different GAG species present in the urine. Urine samples were collected and stored at $-20^{\circ} \mathrm{C}$ until assayed. Normal cat urine was obtained from cats outside the colony. Samples were prepared using cetylpyridinium chloride precipitation for HRE on cellulose acetate strips (22). Total uronic concentrations of prepared samples were determined using the hydroxydiphenyl method (23) and approximately the same amounts ( $\mu$ g uronic) were loaded for HRE on cellulose acetate strips. GAGs were visualized by staining with Alcian blue. By this method, DS in MPS VI urine characteristically migrates as three distinct bands (DS1 and a DS2 doublet), probably due to differences in degree of sulfation (Hopwood, J., unpublished observation). Densitometric estimations of the approximate relative proportions of total DS (DS1 + DS2) were expressed as a percentage of total GAG, in the urine of cats $1 \mathrm{yr}$ or older (except for P/Ps) (22). The relative proportions of the different GAG species vary in young cats (Crawley, A., unpublished observation), hence urine from cats $<1 \mathrm{yr}$ old was excluded to minimize variability.

Leukocyte morphology. For light microscopy, air-dried blood films were stained with May-Grunwald Giemsa and examined at a magnification of 400-1,000. For electron microscopy, buffy coats (prepared from venous blood collected into EDTA) were fixed in 1\% glutaraldehyde $/ 4 \%$ paraformaldehyde in $0.1 \mathrm{M}$ sodium cacodylate buffer, $\mathrm{pH}$ 7.2 , for $60 \mathrm{~min}$ at room temperature, en bloc stained with saturated uranyl acetate in $70 \%$ methanol, then postfixed in $1 \%$ osmium tetroxide, dehydrated, and embedded in Spurr's resin. 1- $\mu$ m-thick sections were stained with toluidine blue and then ultrathin sections were cut and stained with $2 \%$ uranyl acetate $/ 1 \%$ lead citrate and examined with a Hitachi H-7000 electron microscope.

Clinical and radiological examination. A blinded operator performed slit lamp examinations of the corneas in the oldest available cats of each genotype without anesthesia $(\mathrm{P} / \mathrm{N}, 3.8-6.6 \mathrm{yr}$; N/N, $2 \mathrm{mo}$; +/P, 1.2-1.7 yr; +/N, $2.5 \mathrm{mo} ;+/+, 7 \mathrm{mo} ; \mathrm{P} / \mathrm{P}, 5 \mathrm{mo})$. Two additional $\mathrm{N} / \mathrm{N}$ cats (4 $\mathrm{yr}$ old ) were examined for corneal clouding without the slit lamp. Corneal clouding in $\mathrm{P} / \mathrm{Ps}$ is apparent without the aid of a slit lamp from as early as 6-7 wk of age. Cervical spine flexibility was subjectively measured by determining the ability to move the head laterally.

Standardized radiological examination under general anesthesia was as described previously (13). Dimensions of the fifth lumbar vertebra, third cervical vertebra, right tibia, and right patella were measured directly from radiographs (19). Magnification error was assumed to be small due to the large focal film distance used $(133 \mathrm{~cm})$. Measurements were taken from female cats $>18$ mo of age to compare final adult size among the different genotypes. Numbers of animals in each group were: $+/+,+/ \mathrm{P}$, and $+/ \mathrm{N}(n=9$ combined $), \mathrm{P} / \mathrm{Ns}$ 
$(n=12), \mathrm{N} / \mathrm{Ns}(n=8)$, and P/Ps $(n=4)$. Statistical comparison of bone dimensions between these four groups was performed using one-way ANOVA and the Tukey-HSD test for posttesting, accepting $P<0.05$ as statistically significant. These radiographs and additional radiographs of adult males and cats 11-18 mo old were also examined for qualitative changes in skeletal appearance.

Pathology. Cats of various ages were killed using an overdose of intravenous barbiturate. Various tissues for electron microscopy were fixed in $2 \%$ glutaraldehyde $/ 2 \%$ formalin in $0.1 \mathrm{M}$ sodium cacodylate buffer, $\mathrm{pH} 7.2$, overnight at $4^{\circ} \mathrm{C}$, then postfixed in $1 \%$ osmium tetroxide before routine processing and embedding in Spurr's resin. 1- $\mu$ m-thick survey sections stained with toluidine blue were evaluated at a magnification of 100-400 to assess overall distribution of vacuolation due to lysosomal storage. Cross sections of rib cartilage samples surrounded by outer perichondral connective tissue were taken from approximately midway along the cartilage portion of the rib. Articular cartilage sections were cut from the articular surface through to the subchondral bone. Tissue from both colony bred and external normal/ normal cats were examined as controls. The majority of noncartilaginous tissue was also evaluated further under electron microscopy for the presence of abnormal lysosomal vacuolation, particularly tissue from the oldest available animals for each genotype (P/Ns up to 6.5 $\mathrm{yr} ; \mathrm{N} / \mathrm{Ns}$ up to $4.3 \mathrm{yr}$ ). Postmortem of adult cats included examination of the shoulder and stifle joints.

\section{Results}

Genotype analysis: origin of the D520N mutation. Genotype analysis is summarized in the legend to Fig. 1. The pedigree of our colony shows the origin of both the L476P and D520N al-

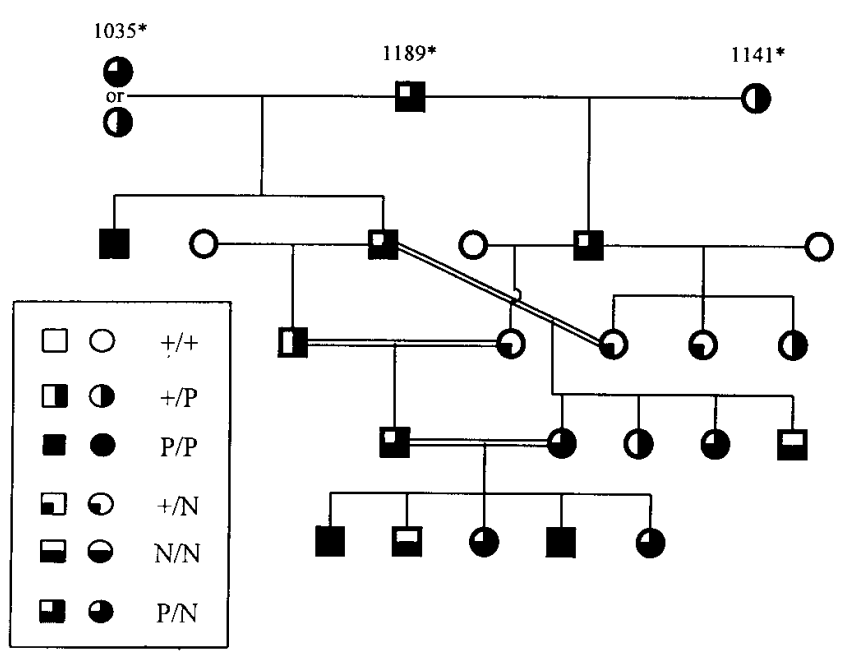

Figure 1. Pedigree of the MPS VI cat colony showing origin of both the L476P and D520N alleles in founder heterozygote cats (asterisks) imported from the United States. Identification numbers of these individuals are also shown. DNA was not available from cats 1035 and 1189. However, all remaining cats were genotyped by PCR-based mutation analysis. The $\mathrm{P} / \mathrm{N}$ genotype of cat 1189 was deduced from breeding outcomes. This cat had an abnormally low leukocyte 4 S/ $\beta$ hex ratio of 0.11 (see normal reference ranges in Table I). However, the genotype of cat 1035 could not be completely deduced. This cat may have been a compound heterozygote $(\mathrm{P} / \mathrm{N})$ as she also had a moderately low leukocyte $4 \mathrm{~S} / \beta$ hex ratio of 0.19 , although she may have been a $+/ \mathrm{P}$ heterozygote. Males and females are represented by square and round symbols, respectively. See figure for description of symbols which represent the six possible genotypes within the colony. Severely affected MPS VI cats are represented by fully shaded symbols $(\mathrm{P} / \mathrm{P})$. Double parallel lines indicate consanguinity. leles in one of the original imported heterozygote cats (cat 1189) (Fig. 1). The D520N mutation appears to have an autosomal recessive mode of inheritance (data not shown), and was not detected in all P/Ps tested $(n=39)$, indicating that the two mutations are not linked. The D520N mutation was also not present in normal cats unrelated to the colony $(n=23)$.

Enzymology. $\mathrm{P} / \mathrm{Ps}, \mathrm{P} / \mathrm{Ns}$, and $\mathrm{N} / \mathrm{Ns}$ all had significantly lower leukocyte $4 \mathrm{~S} / \beta$ hex ratios than $+/+,+/ \mathrm{P}$, and $+/ \mathrm{N}$ cats (Table I). $4 \mathrm{~S} / \mathrm{\beta}$ hex ratios in $\mathrm{P} / \mathrm{Ps}$ and $\mathrm{P} / \mathrm{Ns}$ were statistically different from N/Ns (ANOVA; $P<0.001$ and Tukey-HSD at $P<0.05) .+/ \mathrm{P}$ and $+/ \mathrm{N}$ heterozygotes showed enzyme ratios approximately one-third of $+/+$. The vast majority of cats were 2-3 mo old at the time of leukocyte collection for enzymology, except $+/+$ cats, which were obtained from outside the colony and were usually adult at the time of sampling. Additional $+/+$ cats bred within the colony and sampled at 3 mo old had much lower leukocyte $4 \mathrm{~S} / \beta$ hex ratios $($ mean $\pm \mathrm{SD}=$ $1.25 \pm 0.41, n=5$ ). This adds support to previously unpublished observations that the $4 \mathrm{~S} / \beta$ hex ratio may alter with age, possibly due to changes within the white cell population, and this may help to explain why $+/ \mathrm{P}$ and $+/ \mathrm{N}$ heterozygotes had mean ratios less than the expected half of $+/+$ ratios.

Qualitative urinalysis. Clearly visible DS bands were seen in the majority of P/Ns and N/Ns (mean \pm SD of $\% \mathrm{DS}=36 \pm 6$, and $32 \pm 4, n=16$ for both groups), however the intensity of the bands was not as heavy as seen in $\mathrm{P} / \mathrm{P}$ cats $(\% \mathrm{DS} \geq 60 \%$ in 6-mo-old cats and older). Very faint bands corresponding to DS were observed in over half of the $+/+$ cats (mean \pm SD of $\% \mathrm{DS}=17 \pm 6, n=6),+/ \mathrm{P}$ cats $($ mean $\pm \mathrm{SD}$ of $\% \mathrm{DS}=23 \pm 3$, $n=6)$, and $+/ \mathrm{N}$ cats $($ mean $\pm \mathrm{SD}$ of $\% \mathrm{DS}=18 \pm 8, n=4)$.

Leukocyte morphology. By light microscopy, coarse basophilic cytoplasmic granulation was observed in neutrophils and basophils in $\mathrm{P} / \mathrm{Ps}$, and some lymphocytes contained vacuoles (Fig. 2, $A$ and $B$ ), as described previously (24). The normal granules of eosinophils did not stain, with the granules appearing as empty vacuoles (Fig. $2 A$ ). Abnormal neutrophil granulation was also observed in $\mathrm{P} / \mathrm{Ns}$ and $\mathrm{N} / \mathrm{Ns}$, with intensity ranging from normal or fine to very heavy basophilic granulation (Fig. 2, $C$ and $D$ ). Basophils also had variable numbers of abnormal basophilic cytoplasmic granules with variable staining intensity (Fig. 2 D), some with a similar appearance to those found in P/Ps, and some almost normal. Eosinophils and lymphocytes were normal (Fig. $2 C$ ). There was no obvious difference in leukocyte morphology between N/Ns and P/Ns. No abnormal leukocyte morphology was observed in $+/ \mathrm{P},+/+$ (Fig. 2, $E$ and $F$ ), and $+/ \mathrm{N}$ cats (not shown).

Table I. Peripheral Leukocyte 4S/Bhex Ratios in Cats with Six Different Genotypes

\begin{tabular}{|c|c|c|c|}
\hline Genotype & $4 \mathrm{~S} /$ Bhex ratio & $4 \mathrm{~S} / \beta$ hex ratio range & $n$ \\
\hline$+1+$ & $2.32 \pm 0.99 *$ & $0.94-4.0$ & 16 \\
\hline$+/ \mathrm{P}$ & $0.874 \pm 0.499$ & $0.36-2.5$ & 21 \\
\hline$+/ \mathrm{N}$ & $0.831 \pm 0.557$ & $0.23-2.5$ & 30 \\
\hline $\mathrm{N} / \mathrm{N}$ & $0.052 \pm 0.047$ & $0-0.19$ & 29 \\
\hline $\mathrm{P} / \mathrm{N}$ & $0.028 \pm 0.024^{\ddagger}$ & $0-0.105$ & 38 \\
\hline $\mathrm{P} / \mathrm{P}$ & $0.008 \pm 0.008^{\S}$ & $0-0.018$ & 15 \\
\hline
\end{tabular}

*Values are mean $\pm 1 \mathrm{SD} ; n$, number of cats in each group; ${ }^{\ddagger} P<0.05$, $\mathrm{P} / \mathrm{N}$ vs. $\mathrm{N} / \mathrm{N} ;{ }^{\S} \mathrm{P}<0.05, \mathrm{P} / \mathrm{P}$ vs. N/N. 

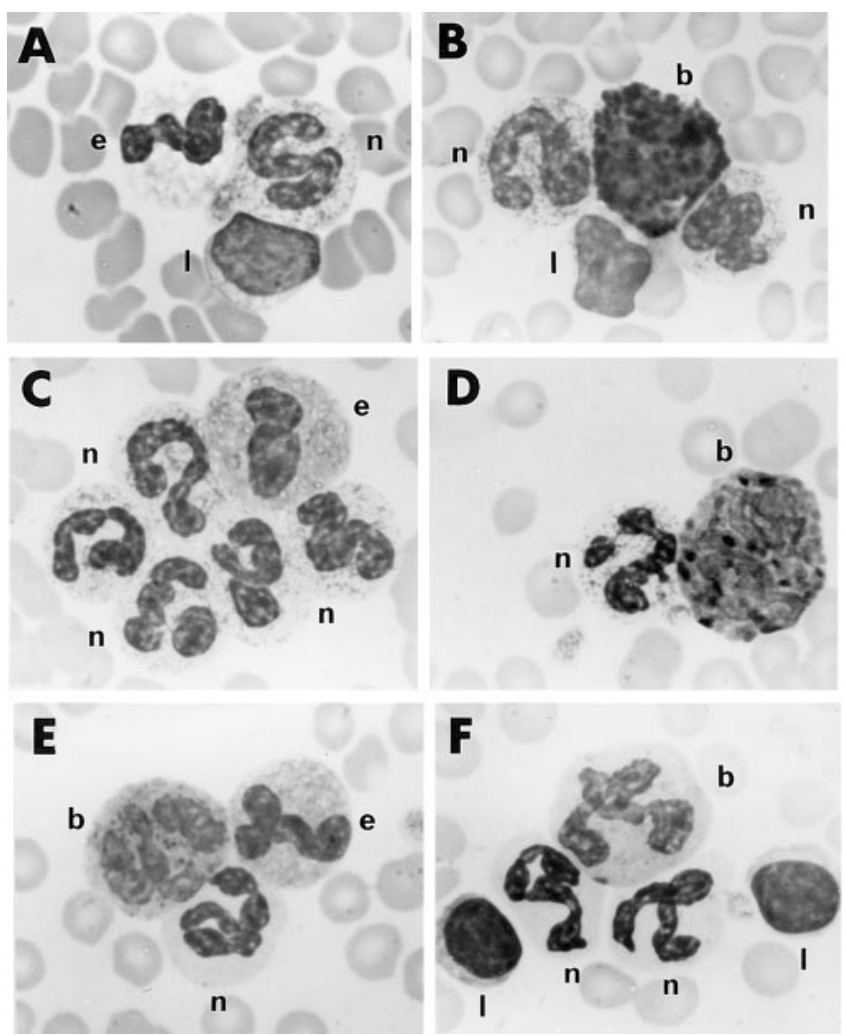

Figure 2. Light microscopy of peripheral leukocytes. $e$, Eosinophil; $n$, neutrophil; $l$, lymphocyte; $b$, basophil. ( $A$ ) P/P (MPS VI severe), with an abnormal nonstaining eosinophil, an abnormal neutrophil with heavy basophilic granulation in the cytoplasm, and an abnormal lymphocyte with several cytoplasmic vacuoles; $(B)$ P/P (MPS VI severe), with an abnormal basophil with intensely basophilic granules obscuring the nucleus, between two abnormal neutrophils showing heavy basophilic granulation, and a normal lymphocyte; $(C) \mathrm{P} / \mathrm{N}$, showing a normal staining eosinophil surrounded by five abnormal neutrophils with basophilic cytoplasmic granulation of variable intensity; $(D) \mathrm{N} / \mathrm{N}$, with an abnormal neutrophil containing basophilic granulation in the cytoplasm and an abnormal basophil with increased basophilic staining of the cytoplasmic granules; $(E)+/ \mathrm{P}$ heterozygote, with a normal appearing basophil showing irregular but slight basophilic staining of the cytoplasm, and a normal neutrophil with a clear cytoplasm, and a
Corresponding to changes observed by light microscopy, abnormal inclusions or altered specific granules were observed by electron microscopy in neutrophils, eosinophils, and basophils in P/Ps (Fig. $3 A$ ), as described previously $(7,24)$. Similar but fewer abnormal inclusions were observed in some neutrophils in $\mathrm{P} / \mathrm{Ns}$ and $\mathrm{N} / \mathrm{Ns}$; however, eosinophils and basophils appeared normal (Fig. 3 B).

Clinical and radiographic examination. By slit lamp examination, from physical appearance and flexibility, and from bone dimensions from radiographs at all ages measured, $\mathrm{P} / \mathrm{Ns}$ and $\mathrm{N} / \mathrm{Ns}$ were indistinguishable from $+/+,+/ \mathrm{P}$, and $+/ \mathrm{N}$ cats, with no statistical significance between these groups for bone dimensions. However, P/Ps exhibited corneal clouding, progressive reduction in flexibility with increasing age, significant reduction in dimensions of all bones measured compared with the other five genotypes, and characteristic skeletal changes observed radiographically as described previously (25). These findings have been summarized in Table II together with additional observations outlined below.

However, on radiographs of $\mathrm{P} / \mathrm{Ns}$, bilateral degenerative changes were observed in $64 \%$ of shoulder (scapulohumeral) joints (Table III), with mild to severe remodeling of the caudal aspect of the proximal humeral epiphysis (Fig. 4, $A-C$ ). The degree of severity of degenerative changes in the shoulder was quite variable and did not appear to be directly correlated with age. The degenerative joint changes observed were not as severe as those seen in P/Ps, which included almost complete loss of the proximal humeral epiphysis (Fig. $4 D$ ). Mild remodeling changes of the proximal humeral epiphysis were present in only 1 (6\%) 1.3 -yr-old N/N of 18 examined with this genotype (Table III). The genotype of this cat was confirmed from two separate blood samples. The remaining N/Ns appeared normal (Fig. $4 E$ ). No degenerative shoulder changes were observed on radiographs from 21 additional cats with $+/+,+/ \mathrm{P}$, and $+/ \mathrm{N}$ genotypes (Table III).

normal staining eosinophil; and $(F)+/+$ cat, with a normal basophil with almost no staining of cytoplasmic granules, two normal neutrophils with clear cytoplasm, and two normal lymphocytes. Original magnification, ×400 (May-Grunwald Giemsa).
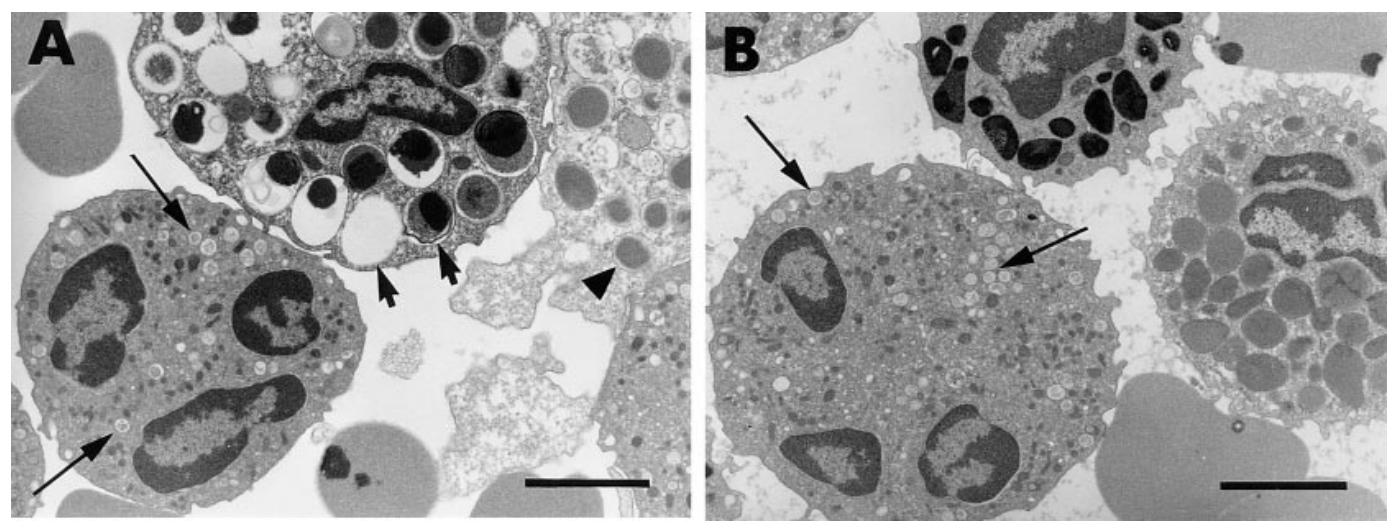

Figure 3. Ultrastructural detail of a neutrophil (bottom left), eosinophil (top center), and basophil (right) in $(A)$ a $\mathrm{P} / \mathrm{P}$ cat and $(B)$ a $\mathrm{P} / \mathrm{N}$ cat. Small abnormal oval to round membrane-bound inclusions, $0.2-0.5 \mu \mathrm{m}$ in diameter, containing fine granular material are observed in neutrophils in both genotypes (long thin arrows, $A$ and $B$ ). The eosinophil-specific granules in the $\mathrm{P} / \mathrm{P}$ are se-

verely altered, with either empty specific granules (short thick arrows, $A$ ), or containing variable amounts of granular or lamellar material. Basophil-specific granules in the $\mathrm{P} / \mathrm{P}$ genotype are also modified with fine fibrillar material at the periphery of the granules (arrowhead, $A$ ).

Ultrastructure of leukocytes in N/Ns was no different from P/Ns. Bar, $2 \mu \mathrm{m}$. 
Table II. Summary of Feline MPS VI Genotype and Resulting Phenotype

\begin{tabular}{|c|c|c|c|c|c|c|c|c|}
\hline Genotype & $\begin{array}{l}\text { Mean white cell } \\
4 \mathrm{~S} / \beta \text { hex ratio* } \\
(\% \text { normal } \pm 1 \mathrm{SD})\end{array}$ & DSuria $(\times$ normal $)$ & Skeletal growth & Joint disease ${ }^{\ddagger}$ & $\begin{array}{l}\text { Corneal } \\
\text { clouding }\end{array}$ & $\begin{array}{l}\text { Chondrocyte } \\
\text { inclusions }^{\S}\end{array}$ & $\begin{array}{l}\text { Connective tissue } \\
\text { inclusions }\end{array}$ & $\begin{array}{l}\text { White cell } \\
\text { inclusions }\end{array}$ \\
\hline $\begin{array}{l}\mathrm{P} / \mathrm{P} \\
(\mathrm{L} 476 \mathrm{P} / \mathrm{L} 476 \mathrm{P})\end{array}$ & $\begin{array}{c}0.008 \\
(0.3 \pm 0.3 \%)\end{array}$ & $>3 \times$ & Reduced & Severe & Mild & Severe & Widespread & $\begin{array}{l}\text { Neutrophils } \\
\text { Basophils } \\
\text { Eosinophils } \\
\text { Lymphocytes }\end{array}$ \\
\hline $\begin{array}{l}\mathrm{P} / \mathrm{N} \\
(\mathrm{L} 476 \mathrm{P} / \mathrm{D} 520 \mathrm{~N})\end{array}$ & $\begin{array}{c}0.028 \\
(1.0 \pm 0.8 \%)\end{array}$ & $\sim 1.8 \times$ & Normal & Mild to moderate & Clear & Mild & \pm Normal $^{* *}$ & $\begin{array}{l}\text { Neutrophils } \\
\text { ? Basophils }\end{array}$ \\
\hline $\begin{array}{l}\mathrm{N} / \mathrm{N} \\
(\mathrm{D} 520 \mathrm{~N} / \mathrm{D} 520 \mathrm{~N})\end{array}$ & $\begin{array}{c}0.052 \\
(1.9 \pm 1.7 \%)\end{array}$ & $\sim 1.6 \times$ & Normal & \pm Normal $^{\|}$ & Clear & Very mild & Normal & $\begin{array}{l}\text { Neutrophils } \\
\text { ? Basophils }\end{array}$ \\
\hline
\end{tabular}

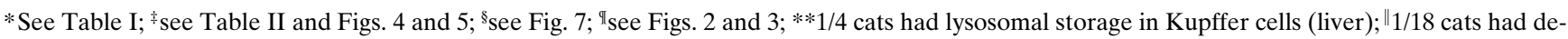
generative joint disease.

A subset of $\mathrm{P} / \mathrm{Ns}$ with degenerative shoulder joint changes also had generally less severe bilateral degenerative changes in the stifle (femorotibial) joints $(20 \%$ of the total number of $\mathrm{P} / \mathrm{Ns}$ examined) (Table III). Remodeling was predominantly localized over the caudoventral aspect of the femoral condyles (Fig. 5, $A$ and $B$ ). Intraarticular calcification without evidence of other changes was observed in an additional three $\mathrm{P} / \mathrm{Ns}$, one $+/ \mathrm{N}$, and three $+/ \mathrm{P}$ heterozygotes; however, this is a common feature of nonspecific stifle joint disease in cats (Allan, G., personal communication) so it was not considered atypical. No stifle abnormalities were observed in N/Ns (Fig. 5 C), $+/+$ cats, and the remaining $+/ \mathrm{P}$ and $+/ \mathrm{N}$ heterozygotes. Radiographic changes of joints in $\mathrm{P} / \mathrm{Ps}$ were severe and as described previously $(7,14,26)$.

Postmortem joint examination. Degenerative joint changes observed on radiographs in $\mathrm{P} / \mathrm{Ns}$ corresponded to severe abnormalities of the articular surface at postmortem in both the shoulder and stifle joints. There were variable extents of fibrillation and erosion of the joint surfaces, particularly over the caudoventral aspect of the proximal humeral epiphysis and on the caudoventral aspect of the distal femoral condyles, with large osteophytes and/or loose bodies present in some joints (Fig.

Table III. Evaluation of Standardized Radiographs for the Presence of Degenerative Joint Disease in the Shoulder and Stifle of Male and Female Cats, with Six Different Genotypes

\begin{tabular}{lrccc}
\hline Genotype & $n$ & Age range & Shoulder pathology & Stifle pathology \\
\hline & & $y r$ & & \\
$+/+$ & 1 & 3.5 & None & None \\
$+/ \mathrm{P}$ & 11 & $0.9-5.8$ & None & None* \\
$+/ \mathrm{N}$ & 9 & $0.9-4.2$ & None & None $^{\ddagger}$ \\
$\mathrm{N} / \mathrm{N}$ & 18 & $0.9-5.2$ & $1 / 18(6 \%)$ & None \\
$\mathrm{P} / \mathrm{N}$ & 25 & $0.9-6.7$ & $16 / 25(64 \%)$ & $5 / 25(20 \%)^{\S}$ \\
$\mathrm{P} / \mathrm{P}$ & 5 & $0.9-2.5$ & $5 / 5(100 \%)$ & $5 / 5(100 \%)$
\end{tabular}

$n$, Number of cats in each group; $* 3 / 11$ had very mild intraarticular calcification; ${ }^{*} 1 / 9$ had very mild intraarticular calcification; ${ }^{\S} 3 / 25$ additional cats had mild to moderate intraarticular calcification without obvious bone remodeling.
6, $A$ and $D$ ). Corresponding to normal joint appearance on radiographs, there were no obvious articular surface abnormalities in some P/Ns (Fig. 6, $B$ and $E$ ). The shoulder joints in a 30-moold $\mathrm{P} / \mathrm{P}$ were more severely affected than any of the $\mathrm{P} / \mathrm{Ns}$, with more extensive remodeling, loss of epiphyseal bone, and loss of articular cartilage (Fig. $6 \mathrm{C}$ ). Stifle joint changes also appeared different in the $\mathrm{P} / \mathrm{P}$ cat, with very thick cartilage without any erosion on the caudoventral region of the distal femoral condyles, but with erosion around the intercondylar notch. The cartilage fibrillation and osteophyte formation was more severe in the remainder of the stifle joint compared with the P/Ns.

Light and electron microscopy. Abnormal chondrocyte morphology was observed in rib, tracheal, and articular cartilage samples from $\mathrm{P} / \mathrm{Ps}, \mathrm{P} / \mathrm{Ns}$, and also N/Ns, with changes seen most clearly in cross sections of rib cartilage. In rib sections from $\mathrm{P} / \mathrm{Ps}$ at all ages, all chondrocytes showed severe lysosomal distension (Fig. $7 A$ ), with larger and more elongated superficial chondrocytes in the outer zone of the cartilage than chondrocytes in the inner layers (Fig. 7, $A$ and $B$ ). In 3-mo-old $+/+,+/ \mathrm{P}$, and $+/ \mathrm{N}$ cats, the superficial chondrocytes were long and slender (Fig. 7, $C$ and $D$ ) with occasional chondrocytes showing single or multiple vacuoles, and chondrocytes in inner layers were broader and rounder, with increasing lipid and occasional vacuoles (Fig. $7 C$ ). In contrast, severe vacuolation and distension of superficial chondrocytes, similar to that seen in $\mathrm{P} / \mathrm{Ps}$, was present in age-matched $\mathrm{P} / \mathrm{Ns}$ (Fig. 7, $E$ and $F)$. Abnormal but less severe vacuolation was also present in the same region in N/Ns (Fig. 7, $G$ and $H$ ), but this was not uniform throughout the circumference of the rib, and chondrocyte morphology was almost normal in some areas of the superficial zone. In both $\mathrm{P} / \mathrm{Ns}$ and N/Ns, the degree of vacuolation decreased to normal levels in the inner cartilage zones. The severity of vacuolation and distension of the superficial chondrocytes appeared to alter with age, and was most severe at $\sim 3$ mo. The location and severity of abnormal vacuolation in rib sections of the different genotypes is summarized in Table IV.

The pattern of abnormal chondrocyte morphology in tracheal cartilage in $\mathrm{P} / \mathrm{Ps}, \mathrm{P} / \mathrm{Ns}$, and $\mathrm{N} / \mathrm{Ns}$ compared with $+/+$ cats was similar to that seen in rib sections. However, the pattern and severity of abnormal chondrocyte morphology was different in articular cartilage. In articular cartilage from $\mathrm{P} / \mathrm{Ps}$, all chondrocytes were increased in size and completely filled 

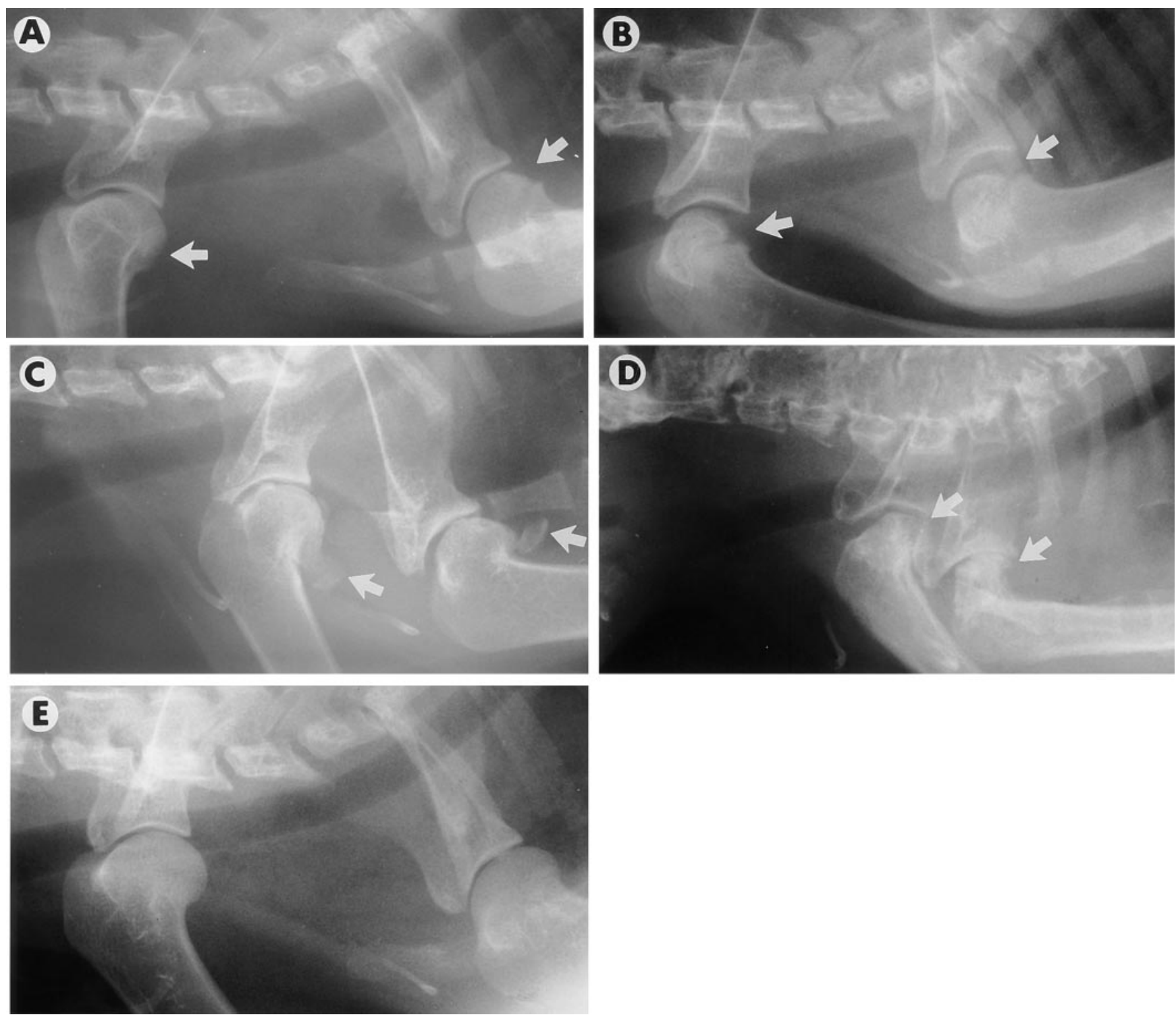

Figure 4. Lateral radiographs of cervical spine and shoulder joints in adult cats (ages in parentheses): P/Ns with $(A)$ mild $(2.6 \mathrm{yr}),(B)$ moderate $(1.2 \mathrm{yr})$, and $(C)$ severe $(6.7 \mathrm{yr})$ remodeling and loss of subchondral bone with mild to severe osteophyte formation in the caudal aspect of the proximal humeral epiphyses in the shoulder (arrows) and normal cervical spine; $(D)$ a $\mathrm{P} / \mathrm{P}$ cat $(2.5 \mathrm{yr})$ with severe degenerative shoulder changes (arrows), and short cervical vertebrae with irregular epiphyses; and $(E)$ an N/N cat (3.9 yr) with normal shoulder joints and cervical spine.

with lysosomal vacuoles. In 3-mo-old P/Ns, abnormal but overall much milder chondrocyte vacuolation was observed than in $\mathrm{P} / \mathrm{Ps}$, with both normal and completely vacuolated chondrocytes scattered throughout all depths of the articular cartilage with no apparent pattern to the degree of vacuolation. Similar but milder changes in abnormal morphology were observed in age-matched $\mathrm{N} / \mathrm{Ns}$. In $+/+,+/ \mathrm{P}$, and $+/ \mathrm{N}$ articular cartilage, only very occasional isolated vacuoles were observed in chondrocytes.

One 6-mo-old $\mathrm{P} / \mathrm{N}$ out of four examined appeared to have mild Kupffer cell storage in the liver (data not shown). Apart from this, no obvious storage was observed in noncartilage connective tissues of $\mathrm{P} / \mathrm{Ns}, \mathrm{N} / \mathrm{Ns},+/ \mathrm{P}$, and $+/ \mathrm{N}$ heterozygotes of various ages compared with $+/+$ cats. Tissue examined included liver, skin, heart valve, aorta, cornea, and hip joint capsule.

\section{Discussion}

Soon after establishing the feline colony, it was evident that abnormally low leukocyte $4 \mathrm{~S} / \mathrm{\beta h}$ ex ratios were found in a number of apparently clinically normal animals, and only one clinically affected MPS VI cat was produced from early breeding attempts. Selection of heterozygote offspring from colony cats outbred with outside normal cats became difficult due to the wide variation in enzymology results obtained (see Table I). This eventually led to heavy selection of clinically normal cats with very low $4 \mathrm{~S} / \beta$ hex ratios as probable MPS VI heterozygotes, which in retrospect were both $\mathrm{P} / \mathrm{Ns}$ and N/Ns. A large range in leukocyte $4 \mathrm{~S} / \beta$ hex ratios was still obtained after the identification of the L476P mutation using PCR-based mutation analysis, which identified both $\mathrm{P} / \mathrm{N}$ and $+/ \mathrm{P}$ genotypes. 

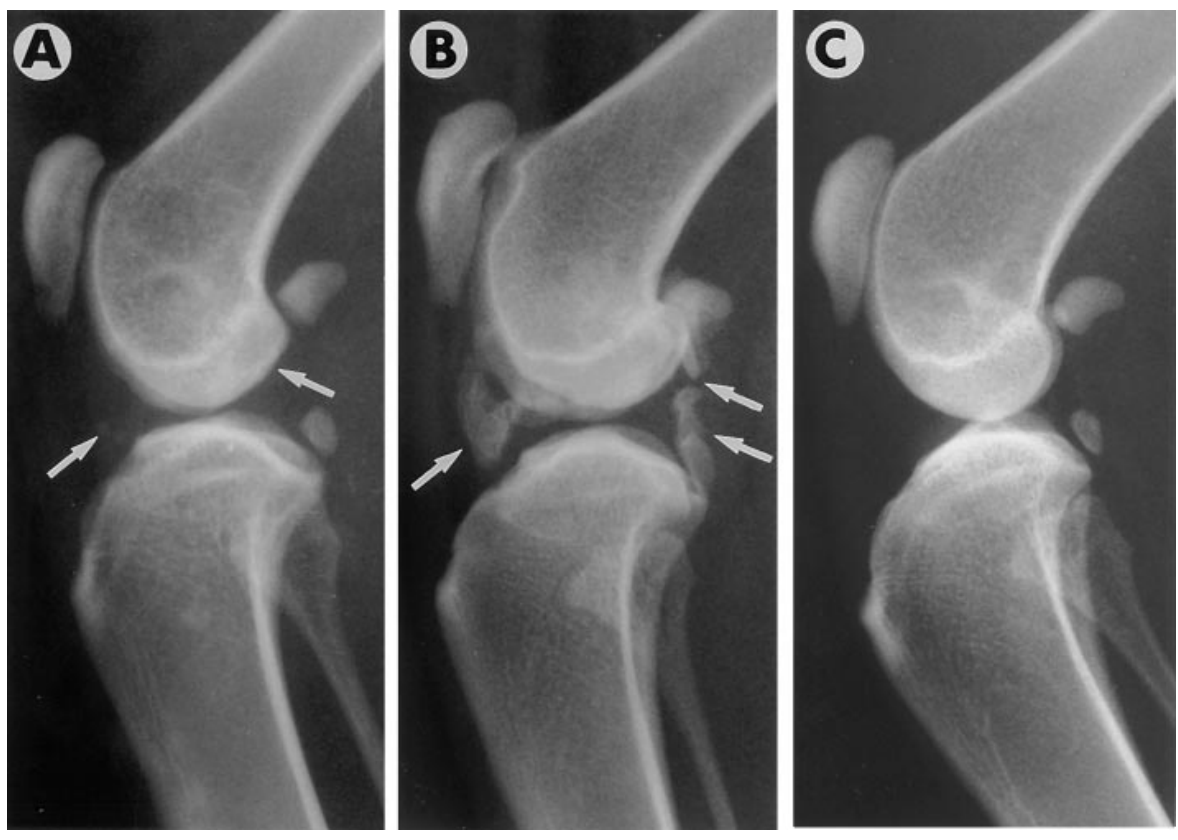

Figure 5. Lateral views of the stifle joint in adult cats (ages in parentheses): $(A) \mathrm{P} / \mathrm{N}$ ( $2.8 \mathrm{yr}$ ) with moderate remodeling of the caudoventral aspect of the femoral condyles (arrow) and very mild intraarticular calcification (arrow); (B) P/N (5.5 yr) with severe remodeling, osteophyte formation, and intraarticular calcification ( $a r-$ rows); and $(C)$ no abnormalities observed in the stifles of $\mathrm{N} / \mathrm{Ns}(5.2 \mathrm{yr})$.

The disparity in enzymology results was clarified when the D520N mutation was discovered.

Despite an outwardly normal physical appearance, $\mathrm{P} / \mathrm{N}$ and $\mathrm{N} / \mathrm{N}$ cats demonstrate biochemical and histological evidence of MPS VI disease, with abnormally low leukocyte 4S/3hex ratios, mild dermatan sulfaturia, and lysosomal storage in chondrocytes and leukocytes. Cultured fibroblasts from N/Ns and $\mathrm{P} / \mathrm{Ns}$ show mild elevations in $\left[{ }^{35} \mathrm{~S}\right]$ sulfate storage, and expression of the mutant D520N 4S in Chinese hamster ovary cells results in normal amounts of a normal sized but unstable protein (Yogalingam, G., J.J. Hopwood, A. Crawley, and D. Anion, manuscript in preparation). Lysosomal storage in only several cell types in $\mathrm{P} / \mathrm{Ns}$ and $\mathrm{N} / \mathrm{Ns}$ suggests that the residual $4 \mathrm{~S}$ activity of this unstable protein is sufficient to prevent the lysosomal accumulation of DS in most tissues, compared with the extensive lysosomal storage in connective tissues in P/Ps.

The only apparent clinical outcome of these findings was the high incidence of degenerative joint disease in $\mathrm{P} / \mathrm{Ns}$. These results are summarized in Table II. The clinical and radiographic features of the joint disease in $\mathrm{P} / \mathrm{Ns}$ were not characteristic of other known causes of arthritis in cats, including rheumatoid arthritis, periosteal proliferative polyarthritis, and feline idiopathic polyarthritis $(27,28)$ (Allan, G., personal communication). Excessive calcification observed in the stifle of one cat is also likely to be seen in hypervitaminosis A. However, the subchondral bone changes and remodeling in both the shoulder and stifle of this cat were atypical (Allan, G., personal communication).

Because of increased longevity of bone marrow transplanted MPS patients and identification of more patients with less severe phenotypes due to improved diagnostic methods, greater numbers of MPS patients are surviving for longer periods of time. New management problems with these patients are emerging, but the future course of their disease is largely unknown. Degenerative joint changes have been reported in several adult MPS VI patients (Hopwood, J., unpublished observations), although to our knowledge, there is only one pub- lished report of severe arthritic changes in the hips and shoulders of a 27-yr-old MPS VI patient at postmortem (29). Initial diagnosis in less severe MPS VI patients is often bilateral Perthes disease $(4,30)$, and bilateral hip replacements have been performed in some patients (4). The lack of description of gross joint pathology may be due to the small numbers of MPS VI patients who survive long enough for possible degenerative joint changes to develop, and also the difficulty in obtaining joints for examination. Our results from the mild MPS VI cat model suggest that degenerative joint changes in MPS VI patients may be an important clinical problem, and that chondrocytes have the greatest $4 \mathrm{~S}$ requirements of all cell types. Therefore, this site of pathology should be an important target for gene product or gene replacement therapies.

Chondrocytes are normally responsible for production and continued maintenance of the surrounding cartilage matrix including the changes necessary for matrix to undergo mineralization at the growth plate, the major site responsible for bone growth. The pathogenesis of abnormal bone growth typical of most of the MPS types is unknown. However, the characteristic severe lysosomal storage in chondrocytes indicates that they are closely implicated in this abnormal process. The severity and extent of lysosomal inclusions in chondrocytes in the three abnormal genotypes correlated closely with abnormal skeletal growth and joint disease, resulting in three different phenotypes: $\mathrm{P} / \mathrm{Ps}$ with severe skeletal and joint disease, $\mathrm{P} / \mathrm{Ns}$ with normal skeletal appearance but moderate joint disease, and N/Ns with both normal skeletal appearance and normal joints. This indicates that partial correction of storage in chondrocytes is sufficient for skeletal growth to proceed normally. It also suggests that if leukocyte $4 \mathrm{~S} / \beta$ hex ratios directly reflect the enzyme levels in other cell types, then theoretically only small increases in enzyme activity in cell types involved in bone growth would lead to normal skeletal growth.

In enzyme replacement therapy studies from birth in $\mathrm{P} / \mathrm{P}$ cats (severe MPS VI phenotype), a dose-related improvement or normalization in skeletal growth and bone histomorpho- 

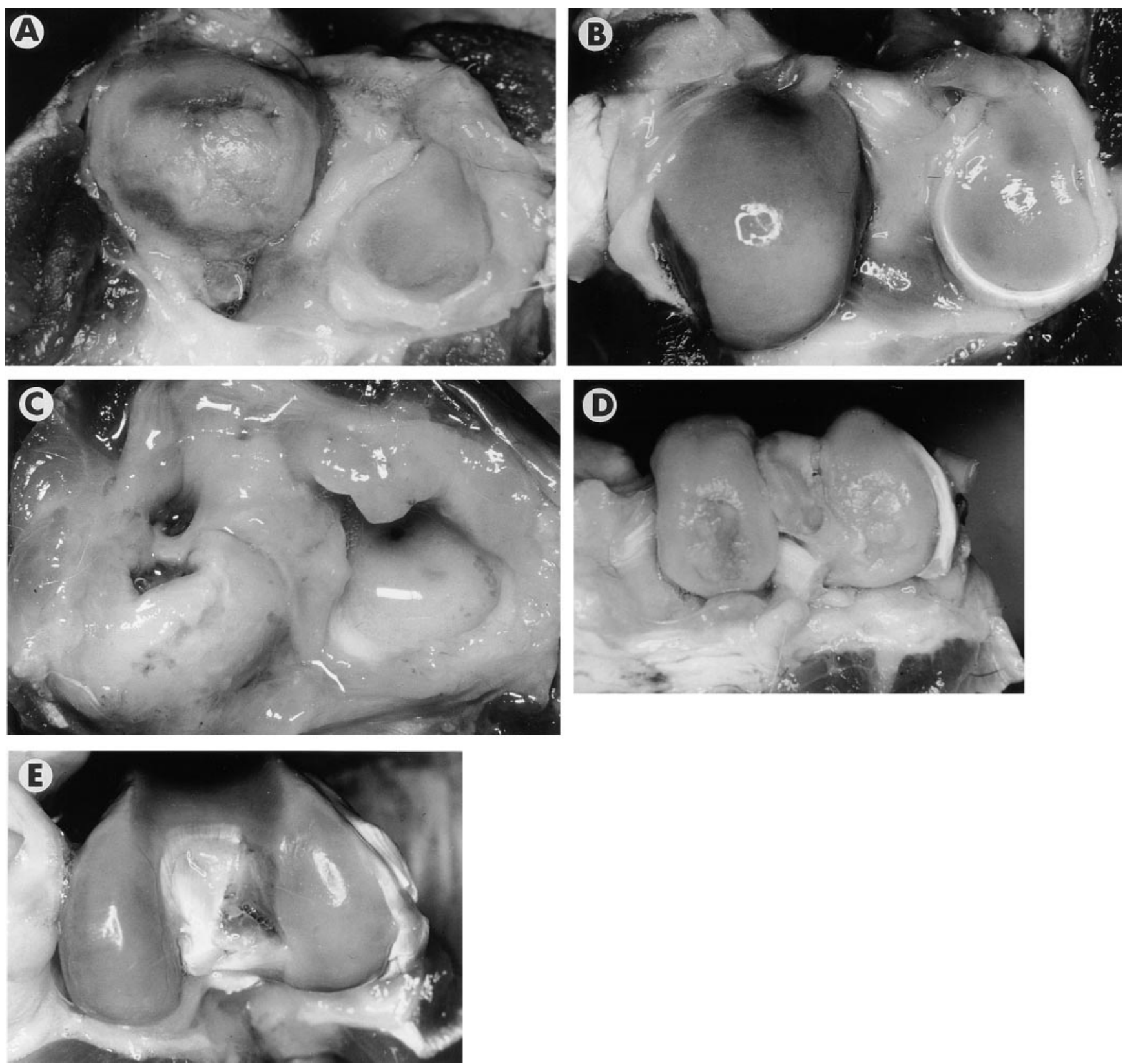

Figure 6. Articular surfaces at postmortem. (A) Shoulder joint from a 6.6-yr-old $\mathrm{P} / \mathrm{N}$ showing severe degenerative changes in articular cartilage with erosion, loose bodies, and ventral osteophytes corresponding to the same regions on radiographs (see Fig. $4 C$ ); $(B)$ normal articular surface in the shoulder joint of a 2.3-yr-old $\mathrm{P} / \mathrm{N} ;(C)$ shoulder joint from a 2.5-yr-old $\mathrm{P} / \mathrm{P}$ with severe remodeling and loss of articular cartilage surface, and eburnation of subchondral bone, corresponding to the same regions on radiographs (see Fig. $4 D$ ); $(D)$ caudoventral aspect of distal femoral condyles (stifle joint) in a 5.5-yr-old $\mathrm{P} / \mathrm{N}$ with severe focal erosion of articular cartilage, corresponding to the same regions on radiographs (see Fig. $5 B$ ); and $(E)$ normal articular surface in the stifle joint of a 2.3 -yr-old $\mathrm{P} / \mathrm{N}$.

metric parameters was observed. However, degenerative joint changes and chondrocyte inclusions were unchanged at all dose rates $(14,19)$. This improvement in skeletal growth and bone parameters correlated directly with a dose-related increase in bone formation rate (19). Osteoblasts are responsible for new bone deposition, and high enzyme levels found in bone marrow in distribution studies in normal cats would suggest that enzyme was available to osteoblasts and possibly also the lower growth plate regions resulting in this improved skeletal growth. Lack of correction of chondrocyte pathology in
$\mathrm{P} / \mathrm{P}$ cats that underwent enzyme replacement therapy and negligible levels of enzyme in cartilage in distribution studies (13) are evidence of poor diffusion of recombinant human $4 \mathrm{~S}$ through cartilage matrix with insufficient levels of enzyme reaching chondrocytes. Mannose-6-phosphate receptor-mediated correction of storage in cultured chondrocytes indicates that chondrocytes have the appropriate cell surface receptors for enzyme uptake once sufficient enzyme levels are available (31). There is a need to improve targeting of therapies to chondrocytes, and the mild MPS VI models in P/N and N/N cats 

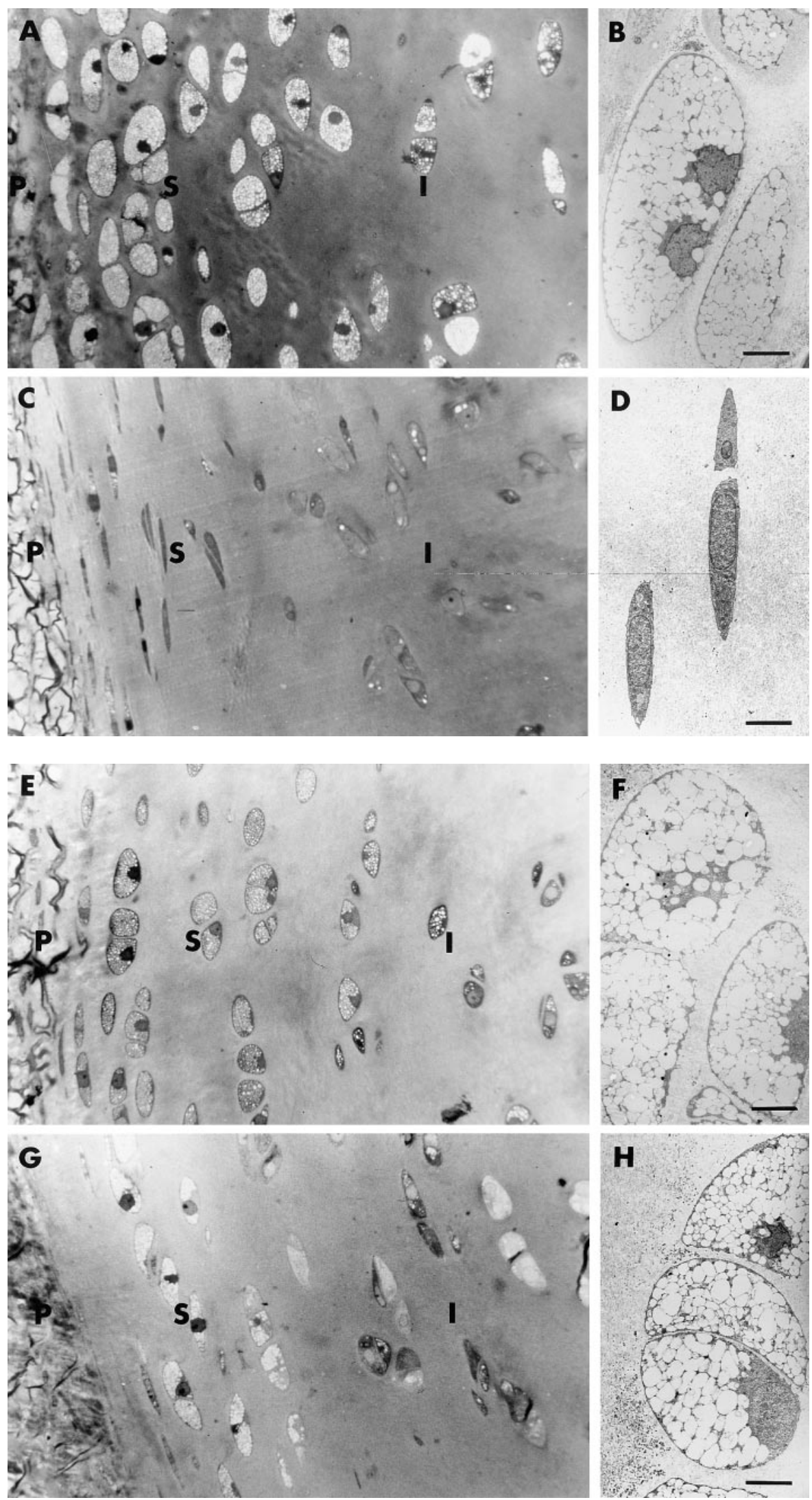

Figure 7. Rib cartilage sections from 3-mo-old cats. ( $A, C, E$, and $G$ ) Toluidine blue-stained $1-\mu \mathrm{m}$-thick sections orientated with the perichondrial connective tissue $(P)$ on the left, superficial cartilage zone $(S)$ in the middle, and inner cartilage zones on the right $(I)$, original magnification $\times 400$. $(B, D, F$, and $H)$ Electron micrographs show the corresponding ultrastructure of chondrocytes in the superficial zones of the rib cartilage (magnification constant, bar, $5 \mu \mathrm{m}$ ). ( $A$ and $B$ ) Severe lysosomal storage and distension of all chondrocytes in all zones and fibroblasts in the perichondrial connective tissue was observed in $\mathrm{P} / \mathrm{Ps}$; $(C$ and $D)$ minimal vacuolation was present in chondrocytes in $+/ \mathrm{P}$ heterozygotes ( $+/ \mathrm{N}$ and $+/+$ not shown) with occasional chondrocytes showing single or multiple vacuoles and increasing lipid toward the inner zone; $(E$ and $F$ ) severe distension and lysosomal vacuolation was observed in chondrocytes in the superficial zone in $\mathrm{P} / \mathrm{Ns}$, and to a slightly lesser degree in N/Ns $(G$ and $H)$. However, the degree of vacuolation decreased to normal levels in the inner cartilage zones ( $E$ and $G$ ). 
Table IV. Location and Severity of Lysosomal Inclusions in Rib Cartilage Sections of 3-mo-old Cats with Six Different Genotypes

\begin{tabular}{lcclc}
\hline Genotype & $n$ & $\begin{array}{c}\text { Perichondrial } \\
\text { cells }\end{array}$ & $\begin{array}{c}\text { Superficial chondrocytes } \\
\text { (superficial zone) }\end{array}$ & $\begin{array}{c}\text { Mature chrondrocytes } \\
\text { (inner zones) }\end{array}$ \\
\hline$+/+$ & 3 & Normal & Normal & Normal \\
$+/ \mathrm{P}$ & 2 & Normal & Normal* & Normal \\
$+/ \mathrm{N}$ & 1 & Normal & Normal & Normal \\
N/N & 2 & Normal & Mild to moderate & Normal \\
P/N & 3 & Normal & Moderate to severe & Normal \\
P/P & 2 & Severe & Severe & Severe \\
& & & &
\end{tabular}

$n$, Number of cats in each group; *some inclusions in these cells are normal.

provide the opportunity to study this cell type in vivo in isolation from other pathologies.

Cartilage is composed of a meshwork of predominantly type II collagen fibrils and proteoglycans that interact to form a matrix that can normally withstand mechanical stresses. $\mathrm{Mu}-$ tations in the type II procollagen gene have been shown to cause primary osteoarthritis in humans (32) and transgenic mice (33). Thinner type II collagen fibers associated with osteoarthritis have also been observed in transgenic mice expressing abnormal type IX collagen (34) adding to the evidence that type IX collagen plays a role in regulating type II collagen fibrillogenesis and matrix integrity (35). Decorin, a cartilage proteoglycan containing DS, has also been shown to inhibit collagen type I and II fibrillogenesis in vitro $(36,37)$. This has led us to speculate that impaired DS degradation in $\mathrm{P} / \mathrm{P}$ and $\mathrm{P} / \mathrm{N}$ chondrocytes leads to accumulation of $\mathrm{DS}$ in the articular cartilage matrix causing altered collagen fibrillogenesis and matrix structural integrity, resulting in degenerative joint disease. Abnormal subchondral bone almost certainly results in the more severe degenerative joint disease observed in $\mathrm{P} / \mathrm{Ps}$. Detailed ultrastructural examination of cartilage from both genotypes should clarify this, and any differences may also help to improve understanding of the abnormal skeletal growth in P/Ps and may further knowledge of cartilage structure and factors that maintain normal matrix function.

In one of the original feline MPS VI papers, in addition to describing MPS VI in three unrelated families of Siamese cats, a clinically normal family 3 obligate heterozygote male with leukocyte $4 \mathrm{~S}$ activities consistently in the affected range was also observed (7). This cat had no radiographic features of MPS VI, no corneal clouding, and lacked excessive urinary GAG and coarse leukocyte granulation. Since the D520N mutation originated in our family 3 heterozygote founder cats imported from the United States (Fig. 1), it is likely that this cat was a $\mathrm{P} / \mathrm{N}$. The clinical findings reported were consistent with our observations of $\mathrm{P} / \mathrm{Ns}$, since some individuals had no abnormal radiographic changes, leukocyte granulation was variable and mild in some cats, and total urinary GAG was also indistinguishable from normal (data not shown). Screening for the L476P and D520N alleles in established MPS VI cat colonies, new feline MPS VI cases, and Siamese cats in general would be helpful to clarify previous observations made in MPS VI cats and to establish if these mutations are common in the general Siamese cat population. A very useful and rapid screening method for $\mathrm{P} / \mathrm{N}$ and $\mathrm{N} / \mathrm{N}$ cats was the presence of obvious leu- kocyte inclusions on routine blood films (Fig. 2) despite a normal physical appearance, although these inclusions are not found using some alternative stain preparations such as DiffQuik (our unpublished observations).

The lack of eosinophil staining in blood films of $\mathrm{P} / \mathrm{P}$ cats is probably due to extreme modifications of the specific granules observed ultrastructurally. In normal cats, these granules consist of a densely osmiophilic crystalline core, appearing as concentric rings, surrounded by a less dense matrix (38). The eosinophil major basic protein, which strongly binds to eosinophilic dyes due to charge, has been immunolocalized to the core of the eosinophil-specific granule in humans (39) and guinea pigs (40). GAGs have also been demonstrated cytochemically in immature eosinophil-specific granules (41). Although the interactions between these two granule components are poorly defined, it seems probable that modification of the GAGs in the $\mathrm{P} / \mathrm{P}$ eosinophil granules, due to impaired GAG metabolism, affects the charge of the eosinophil major basic protein in the granule core and results in lack of binding by eosinophilic dyes. Eosinophils from clinically affected MPS VI cats have been reported previously to contain both eosinophilic and basophilic granules using a Wright-Giemsa stain (24) which is different from our observations of a complete lack of staining in eosinophils in P/Ps. The origin of the MPS VI affected blood is not stated and it may be possible that these cats had a different genotype resulting in slightly less severe modifications of the eosinophil-specific granules. It is difficult to adequately compare ultrastructural features from the original paper with the $\mathrm{P} / \mathrm{Ps}$ described here to support this hypothesis.

Basophil-specific granules contain mostly 4-sulfated chondroitin and DS in humans (42) and guinea pigs (43), therefore it is likely that the greatly increased basophilia observed in $\mathrm{P} / \mathrm{P}$ basophils is due to increased storage of 4-sulfated GAG in the specific granules.

In conclusion, the clinical, histological, and biochemical features of $\mathrm{P} / \mathrm{N}$ and $\mathrm{N} / \mathrm{N}$ cats indicate that residual enzyme activity in these genotypes is sufficient to prevent the severe MPS VI phenotype seen in P/Ps. Degenerative joint disease in $\mathrm{P} / \mathrm{N}$ cats is probably solely due to consequences of impaired chondrocyte GAG metabolism. Understanding the pathogenesis of this process may provide new insights into cartilage matrix development and organization. It also indicates that chondrocytes have the highest $4 \mathrm{~S}$ requirement of any cell type, and that degenerative joint disease may be an emerging problem in longer lived MPS patients undergoing therapies. Therefore, this should be a focus for further developments in therapies. The possibility of MPS VI in human patients with normal physical phenotypes but with degenerative joint disease of unknown cause should also be considered.

\section{Acknowledgments}

The authors gratefully acknowledge the animal care staff at the Institute of Medical and Veterinary Science for the daily care of the cat colony. We thank Dr. Michael Hammerton for slit lamp examination of the cats, Dr. Graeme Allan for expert advice regarding radiological findings, and Richard Davey for expert assistance with electron microscopy and preparation of figures. We also greatly appreciate assistance from Darren Matthew, Kym Smith (Institute of Medical and Veterinary Science) and the Women's and Children's Hospital Electron Microscopy Unit with electron microscopy, Jennifer Blake and Wendy Norton for assistance with urine electrophoresis, and the staff at Magill Road Veterinary Hospital for collection of normal cat urine. 
We also thank Roland Hermanis for photographic work and Enzo Ranieri for statistical advice.

This work was supported by the Women's and Children's Hospital Foundation, Channel 7 Children's Research Foundation, CSL Limited, and the National Health and Medical Research Council of Australia. The original cats heterozygous for MPS VI (National Institutes of Health grant DK-25759) given by Prof. Mark Haskins from the University of Pennsylvania are gratefully acknowledged.

\section{References}

1. Whitley, C.B. 1993. The mucopolysaccharidoses. In McKusick's Heritable Disorders of Connective Tissue. 5th edition. P. Beighton, editor. Mosby, St. Louis, MO. 367-499.

2. Neufeld, E.F., and J. Muenzer. 1995. The mucopolysaccharidoses. In The Metabolic and Molecular Basis of Inherited Disease. 7th edition. C.R. Scriver, A.L. Beaudet, W.S. Sly, and D. Valle, editors. McGraw-Hill, New York. 24652494.

3. Quigley, H.A., and K.R. Kenyon. 1974. Ultrastructural and histochemical studies of a newly recognized form of systemic mucopolysaccharidosis (Maroteaux-Lamy syndrome, mild phenotype). Am. J. Ophthalmol. 77:809-818.

4. Pilz, H., K. von Figura, and H.H. Goebel. 1979. Deficiency of arylsulfatase B in 2 brothers aged 40 and 38 years (Maroteaux-Lamy syndrome, type B). Ann. Neurol. 6:315-325.

5. Paterson, D.E., G. Harper, H.J. Weston, and J. Mattingley. 1982. Maroteaux-Lamy syndrome, mild form: MPS vi b. Br. J. Radiol. 55:805-812.

6. Tonnesen, T., H.N. Gregersen, and F. Guttler. 1991. Normal MPS excretion, but dermatan sulphaturia, combined with a mild Maroteaux-Lamy phenotype. J. Med. Genet. 28:499-501.

7. Haskins, M.E., P.F. Jezyk, and D.F. Patterson. 1979. Mucopolysaccharide storage disease in 3 families of cats with arylsulfatase B deficiency: leukocyte studies and carrier identification. Pediatr. Res. 13:1203-1210.

8. Breton, L., P. Guerin, and M. Morin. 1983. A case of mucopolysaccharidosis VI in a cat. J. Am. Anim. Hosp. Assoc. 19:891-896.

9. Di Natale, P., T. Annella, A. Daniele, G. Spagnuolo, R. Cerundolo, D. de Caprariis, and A.E. Gravino. 1992. Animal models for lysosomal storage diseases: a new case of feline mucopolysaccharidosis VI. J. Inherit. Metab. Dis. 15: $17-24$.

10. Beekman, G.K. 1993. Mucopolysaccharidosis VI in a kitten: a case report and discussion of feline Maroteaux-Lamy syndrome. Feline Pract. 21:7-11.

11. Haskins, M.E., G.D. Aguirre, P.F. Jezyk, and D.F. Patterson. 1980. The pathology of the feline model of mucopolysaccharidosis VI. Am. J. Pathol. 101: 657-674.

12. Yogalingam, G., T. Litjens, J. Bielicki, A.C. Crawley, V. Muller, D.S. Anson, and J.J. Hopwood. 1996. Feline mucopolysaccharidosis Type VI: characterization of recombinant $\mathrm{N}$-acetylgalactosamine 4-sulfatase and identification of a mutation causing the disease. J. Biol. Chem. 271:27259-27265.

13. Crawley, A.C., D.A. Brooks, V.J. Muller, B.A. Petersen, E.L. Isaac, J. Bielicki, B.M. King, C.D. Boulter, A.J. Moore, N.L. Fazzalari, et al. 1996. Enzyme replacement therapy in a feline model of Maroteaux-Lamy syndrome. $J$. Clin. Invest. 97:1864-1873.

14. Crawley, A.C., K.H. Niedzielski, E.L. Isaac, R.C.A. Davey, S. Byers, and J.J. Hopwood. 1997. Enzyme replacement therapy from birth in a feline model of mucopolysaccharidosis type VI. J. Clin. Invest. 99:651-662.

15. Brooks, D.A., P.A. McCourt, G.J. Gibson, L.J. Ashton, M. Shutter, and J.J. Hopwood. 1991. Analysis of $N$-acetylgalactosamine-4-sulfatase protein and kinetics in mucopolysaccharidosis type VI patients. Am. J. Hum. Genet. 48:710-719.

16. Wicker, G., V. Prill, D. Brooks, G. Gibson, J. Hopwood, K. von Figura, and C. Peters. 1991. Mucopolysaccharidosis VI (Maroteaux-Lamy syndrome). An intermediate clinical phenotype caused by substitution of valine for glycine at position 137 of arylsulfatase B. J. Biol. Chem. 266:21386-21391.

17. Litjens, T., D.A. Brooks, C. Peters, G.J. Gibson, and J.J. Hopwood. 1996. Identification, expression, and biochemical characterization of $N$-acetylgalactosamine-4-sulfatase mutations and relationship with clinical phenotype in MPS-VI patients. Am. J. Hum. Genet. 58:1127-1134.

18. Hopwood, J.J., A. Vellodi, H.S. Scott, C.P. Morris, T. Litjens, P.R. Clements, D.A. Brooks, A. Cooper, and J.E. Wraith. 1993. Long-term clinical progress in bone marrow transplanted mucopolysaccharidosis type I patients with a defined genotype. J. Inherit. Metab. Dis. 16:1024-1033.

19. Byers, S., J.D. Nuttall, A.C. Crawley, J.J. Hopwood, K. Smith, and N.L. Fazzalari. 1997. Effect of enzyme replacement therapy on bone formation in feline model of mucopolysaccharidosis type VI. Bone. 21:425-431.
20. Kampine, J.P., R.O. Brady, J.N. Kanfer, M. Feld, and D. Shapiro. 1966. Diagnosis of Gaucher's disease and Niemann-Pick disease with small samples of venous blood. Science. 155:86-88.

21. Hopwood, J.J., H. Elliott, V.J. Muller, and G.T.P. Saccone. 1986. Diagnosis of Maroteaux-Lamy syndrome by the use of radiolabeled oligosaccharides as substrates for the determination of arylsulfatase B activity. Biochem. J. 234 507-514.

22. Hopwood, J.J., and J.R. Harrison. 1982. High-resolution electrophoresis of urinary glycosaminoglycans: an improved screening test for the mucopolysaccharidoses. Anal. Biochem. 119:120-127.

23. Blumenkrantz, N., and G. Asboe-Hansen. 1973. New method for quantitative determination of uronic acids. Anal. Biochem. 54:484-489.

24. Alroy, J., G.O. Freden, V. Goyal, S.S. Raghavan, and K.L. Schunk. 1989. Morphology of leukocytes from cats affected with alpha-mannosidosis and mucopolysaccharidosis VI (MPS VI). Vet. Pathol. 26:294-302.

25. Konde, L.J., M.A. Thrall, P. Gasper, S.M. Dial, K. McBiles, S. Colgan, and M. Haskins. 1987. Radiographically visualized skeletal changes associated with mucopolysaccharidosis VI in cats. Vet. Radiol. 28:223-228.

26. Cowell, K.R., P.F. Jezyk, M.E. Haskins, and D.F. Patterson. 1976. Mucopolysaccharidosis in a cat. J. Am. Vet. Med. Assoc. 169:334-339.

27. Bennett, D., and A.S. Nash. 1988. Feline immune-based polyarthritis: a study of thirty-one cases. J. Small Anim. Pract. 29:501-523.

28. Bennett, D., and C. May. 1995. Joint diseases of dogs and cats. In Textbook of Veterinary Internal Medicine. 4th edition. S.J. Ettinger and E.C. Feldman, editors. W.B. Saunders Co., Philadelphia. 2032-2077.

29. Keller, C., J. Briner, J. Schneider, M. Spycher, S. Rampini, and R. Gitzelmann. 1987. Mucopolysaccharidosis type VI-A (Maroteaux-Lamy disease) correlation of clinical and anatomo-pathological findings in a 27-year-old patient. Helv. Paediatr. Acta. 42:317-334.

30. Spranger, J.W., F. Koch, V.A. McKusick, J. Natzschka, H.R. Wiedemann, and H. Zellweger. 1970. Mucopolysaccharidosis VI (Maroteaux-Lamy's disease). Helv. Paediatr. Acta. 25:337-362.

31. Fillat, C., C.M. Simonaro, P.L. Yeyati, J.L. Abkowitz, M.E. Haskins, and E.H. Schuchman. 1996. Arylsulfatase B activities and glycosaminoglycan levels in retrovirally transduced mucopolysaccharidosis type VI cells. Prospects for gene therapy. J. Clin. Invest. 98:497-502.

32. Ala-Kokko, L., C.T. Baldwin, R.W. Moskowitz, and D.J. Prockop. 1990 Single base mutation in the type II procollagen gene (COL2A1) as a cause of primary osteoarthritis associated with a mild chondrodysplasia. Proc. Natl. Acad. Sci. USA. 87:6565-6568.

33. Helminen, H.J., K. Kiraly, A. Pelttari, M.I. Tammi, P. Vandenberg, R. Pereira, R. Dhulipala, J.S. Khillan, L. Ala-Kokko, E.L. Hume, et al. 1993. An inbred line of transgenic mice expressing an internally deleted gene for type II procollagen (COL2A1). Young mice have a variable phenotype of a chondrodysplasia and older mice have osteoarthritic changes in joints. J. Clin. Invest. 92: 582-595.

34. Nakata, K., K. Ono, J.I. Miyazaki, B.R. Olsen, Y. Muragaki, E. Adachi, K.I. Yamamura, and T. Kimura. 1993. Osteoarthritis associated with mild chondrodysplasia in transgenic mice expressing alpha-1(IX) collagen chains with a central deletion. Proc. Natl. Acad. Sci. USA. 90:2870-2874.

35. Diab, M. 1993. The role of type IX collagen in osteoarthritis and rheumatoid arthritis. Orthop. Rev. 22:165-170.

36. Vogel, K.G., M. Paulsson, and D. Heinegard. 1984. Specific inhibition of type I and type II collagen fibrillogenesis by the small proteoglycan of tendon. Biochem. J. 223:587-598.

37. Schonherr, E., H. Hausser, L. Beavan, and H. Kresse. 1995. Decorintype I collagen interaction. J. Biol. Chem. 270:8877-8883.

38. Ward, J.M., J.F. Wright, and G.H. Wharran. 1972. Ultrastructure of granulocytes in the peripheral blood of the cat. J. Ultrastruct. Res. 39:389-396.

39. Peters, M.S., M. Rodriguez, and G.J. Gleich. 1986. Localization of human eosinophil granule major basic protein, eosinophil cationic protein, and eosinophil-derived neurotoxin by immunoelectron microscopy. Lab. Invest. 54: 656-662.

40. Lewis, D.M., J.C. Lewis, D.A. Loegering, and G.J. Gleich. 1978. Localization of the guinea pig eosinophil major basic protein to the core of the granule. J. Cell Biol. 77:702-713.

41. Parmley, R.T., M. Takagi, S.S. Spicer, A. Thrasher, and F.R. Denys. 1982. Ultrastructural visualization of complex carbohydrates in eosinophilic leukocytes. Am. J. Anat. 165:53-67.

42. Metcalfe, D.D., C.E. Bland, and S.I. Wasserman. 1984. Biochemical and functional characterization of proteoglycans isolated from basophils of patients with chronic myelogenous leukemia. J. Immunol. 132:1943-1950.

43. Orenstein, N.S., S.J. Galli, A.M. Dvorak, J.E. Silbert, and H.F. Dvorak. 1978. Sulfated glycosaminoglycans of guinea pig basophilic leukocytes. J. Immunol. 121:586-592. 